\title{
Communal Oviposition in the Northern Two-lined Salamander (Eurycea bislineata) in Algonquin Provincial Park, Ontario
}

\author{
DAVID L. LEGROS \\ Department of Biology, Laurentian University, 935 Ramsey Lake Road, Sudbury, Ontario P3E 2C6 Canada; email: dl_legros@ \\ laurentian.ca
}

LeGros, David L. 2011. Communal oviposition in the Northern Two-lined Salamander (Eurycea bislineata) in Algonquin Provincial Park, Ontario. Canadian Field-Naturalist 125(4): 363-365.

\begin{abstract}
While surveying a stream for amphibians in Algonquin Provincial Park, Ontario, Canada, I discovered a clutch of Two-lined Salamander (Eurycea bislineata) eggs on the underside of a partially submerged rock. I counted 165 eggs and measured them using ImageJ from a digital photograph. The quantity of eggs is far greater than any known clutch size for this species, and it was likely deposited by more than one female. This is the first report of communal oviposition in this species in Canada.
\end{abstract}

Key Words: Northern Two-lined Salamander, Eurycea bislineata, communal oviposition site, Algonquin Provincial Park, Ontario.

The Northern Two-lined Salamander (Eurycea bislineata) occurs throughout much of the northeastern United States and adjacent Canada (Petranka 1998), and it can be quite common in suitable habitat (Burton and Likens 1975). The Northern Two-lined Salamander is well studied in parts of its range, and many life history details are known. In Ontario, however, it has been comparatively understudied, and as a result much of the information on Canadian populations is extrapolated from research done by herpetologists working in the United States. One such aspect of the life history of the Northern Two-lined Salamander is oviposition and clutch size.

\section{Observations}

This observation was made on 12 May 2010 during a stream survey in Algonquin Provincial Park, central Ontario, Hunter Township, in the vicinity of Brown Lake, $45^{\circ} 37^{\prime} \mathrm{N}, 78^{\circ} 51^{\prime} \mathrm{W}$. The stream consists of several pools, riffles, and short areas of swift current, and the width ranges from 0.75 to $1.5 \mathrm{~m}$. The stream bottom consists of sand, gravel, and cobble. The margins of the stream have many mossy rocks and wet leaf litter. The surrounding forest is dominated by Sugar Maple (Acer saccharum) and Yellow Birch (Betula alleghaniensis).

The site of oviposition was in a section of fastmoving water, approximately $3 \mathrm{~m}$ upstream of a large pool where over 10 larval $E$. bislineata were found. The stream appeared to have many other rocks suitable for oviposition.

While turning rocks in the stream, I uncovered a clutch of Northern Two-lined Salamander eggs. The cluster of 165 eggs was attached in a single layer to the underside of a rock (Figure 1). The rock, which was roughly triangular in shape, measured about $25 \mathrm{~cm}$ by $20 \mathrm{~cm}$ at the largest points, approximately $250 \mathrm{~cm}^{2}$. Two adult salamanders were also underneath this rock, but they escaped prior to capture. Several digital photos were taken in the field, and the stone was replaced in its original position within minutes.

A second egg mass was found on the same day several metres downstream; it contained approximately
35 eggs. There was no apparent embryonic development in either egg mass, suggesting these eggs had been recently deposited. Over the course of the field season, many other adult and larval E. bislineata were frequently found in this stream.

The digital photo was printed and the eggs were counted on paper. All subsequent measurements were made based on the digital photograph. Using the Vernier callipers present in the photograph for scale, measurements were calibrated using ImageJ (Rasband $2010^{*}$ ). From the digital photo, a subsample of 53 eggs, measured using ImageJ, had a mean diameter of $3.06 \mathrm{~mm}(2.3-3.79 \mathrm{~mm}$, SE 0.367). The surface area of the eggs was also measured using ImageJ, and it occupied $4432 \mathrm{~mm}^{2}$, or roughly $90 \mathrm{~mm} \times 50 \mathrm{~mm}$.

\section{Discussion}

The number of eggs found in this account exceeds that found in Ohio by Bauman and Huels (1982), who found a maximum of 110 and a mean of 39.4 eggs. Wood and McCutcheon (1954) found between 25 and 115 ova (mean of 71.5) in gravid two-lined salamanders in southern Virginia (Eurycea bislineata $\times$ cirrigera). It is clear that the number of eggs found in the first observation in Algonquin Provincial Park came from more than one female, so this likely is an instance of communal oviposition. It is estimated that $7 \%$ of salamanders of the family Plethodontidae exhibit this behaviour, but it is under-reported because of the difficulty in finding salamander eggs (Doody et al. 2009). Two-lined salamanders typically deposit eggs on the undersides of stones or other debris in streams, with females remaining with the clutch, defending them from predators (Petranka 1998). Communal nesting in Eurycea bislineata has been documented in New York (Bishop 1941), Virginia (Wood 1953), and likely in Ohio (Bauman and Huels 1982).

Some researchers suggest that suitable oviposition sites are limited and the small number of sites may limit population size (Stewart 1968). Ideal locations may therefore be used by more than one female. In fact, several brooding females may be found under the 

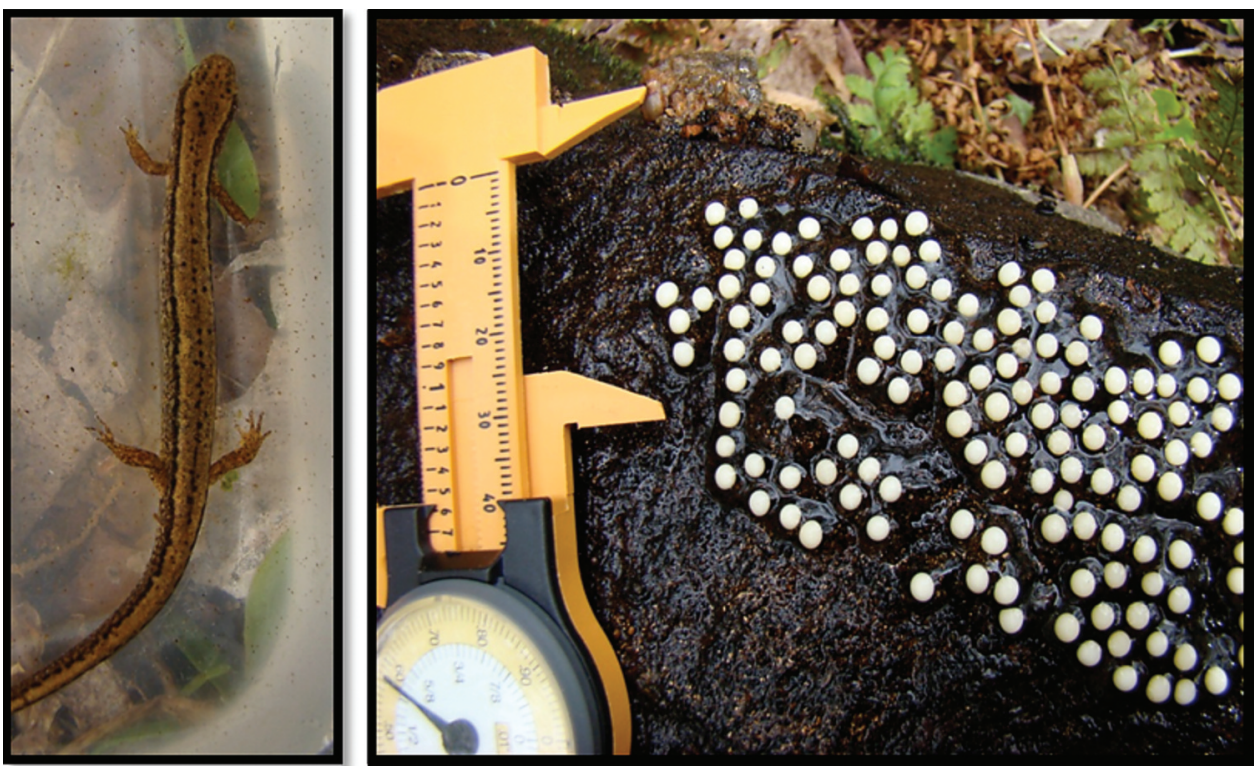

FIGURE 1. Northern Two-lined Salamander (left), Northern Two-lined Salamander eggs attached to the underside of the partially submerged rock (right), Algonquin Provincial Park, 12 May 2010. Note: Not all 165 eggs are in frame. Photo: David LeGros.

same cover object (Petranka 1998). Communal oviposition in a habitat with few suitable sites is logical, but it is not clear why it occurs in habitat that seemingly has an abundance of sites. The best oviposition sites have obvious benefits, such as high hatching success and proximity to good natal habitat (Refsnider and Janzen 2010). Other adaptive factors such as female survivorship and reduced risk of predation of a particular female's eggs may also influence the frequency of communal nesting in salamanders (Doody et al. 2009). In a review of communal oviposition in reptiles and amphibians, (Doody et al. 2009) explained that some species are more likely to oviposit where another female has previously oviposited and hatched young.

To my knowledge, this is the first reported case of communal oviposition of E. bislineata in Ontario. The range of the Northern Two-lined Salamander is surprisingly extensive in Ontario (Desroches et al. 2010) and other eastern Canadian provinces (Cook 1984), but few researchers visit these regions. Continued observation of this species in the northernmost part of its range would be of value.

\section{Acknowledgements}

I would like to thank Shane Pratt for helping with the survey of the stream. This observation could not have been made without the assistance and permission of Algonquin Provincial Park, Ontario Parks (permit number AP-10-DLG). This observation was made as part of research that was supported by funding from David Lesbarrères, Laurentian University and Ontario Parks. I would also like to thank the four anonymous reviewers, the editor and those who encouraged me to write this paper.

Documents Cited (marked * in text)

Rasband, W. S. 2010. ImageJ. U.S. National Institutes of Health, Bethesda, Maryland, U.S.A. http://imagej.nih.gov /ij/.

\section{Literature Cited}

Bauman, W. L., and M. Huels. 1982. Nests of the Two-lined Salamander, Eurycea bislineata. Journal of Herpetology 16(1): 81-83.

Bishop, S. C. 1941. Salamanders of New York. New York State Museum Bulletin 324: 1-365.

Burton, T. M., and G. E. Likens. 1975. Energy flow and nutrient cycling in salamander populations in the Hubbard Brook experimental forest, New Hampshire. Ecology 56: 1068-1080.

Cook, F. R. 1984. Introduction aux amphibiens et reptiles du Canada. Musée nationaux du Canada. Ottawa, Canada.

Desroches, J-F., F. W. Schueler, I. Picard, and L. P. Gagnon. 2010. A herpetological survey of the James Bay area of Quebec and Ontario. Canadian Field-Naturalist 124(4): 299-315.

Doody, S. J., S. Freedberg, and J. S. Keogh. 2009. Communal egg-laying in reptiles and amphibians: evolutionary patterns and hypotheses. Quarterly Review of Biology 84(3): 229-252. 
Petranka, J. W. 1998. Salamanders of the United States and Canada. Smithsonian Institution Press, Washington.

Refsnider, J. M., and F. J. Janzen. 2010. Putting eggs in one basket: ecological and evolutionary hypotheses for variation in oviposition site choice. Annual Review of Ecology, Evolution, and Systematics 41: 39-57.

Stewart, M. M. 1968. Population dynamics of Eurycea bislineata in New York. Journal of Herpetology 2: 176-177.

Wood, J. T. 1953. The nesting of the Two-lined Salamander, Eurycea bislineata, on the Virginia coastal plain. Natural
History Miscellanea of the Chicago Academy of Science 122: $1-7$.

Wood, J. T., and N. H. McCutcheon. 1954. Ovarian egg complements and the nests of the Two-lined Salamander Eurycea $b$. bislineata $\times$ cirrigera, from southeastern Virginia. American Midland Naturalist 52: 433-436.

Received 18 January 2012

Accepted 10 February 2012 